\title{
Cue utilization as a function of drive and operant response contingency
}

\author{
JEROME S. COHEN and B. MICHAEL QUIRT \\ University of Windsor, Windsor, Ontario, Canada N9B $3 P 4$
}

\begin{abstract}
Albino rats under either a high $(2 \mathrm{~g} / \mathrm{day})$ or moderate $(12 \mathrm{~g} / \mathrm{day})$ food deprivation were presented pairings of a brief light-off stimulus with reinforcement. Within each drive level, half the animals received this conditioning superimposed on an already learned FR 20 operant barpress schedule (response-contingent animals). For the remaining animals, the stimulus reinforcement pairings occurred without the bar present (nonresponse-contingent animals). In tests for stimulus-evoked foodcup approaches within FR runs, only contingent animals displayed cue utilization. Within the contingent condition, high drive animals displayed more rapid acquisition of, and more stable cue utilization than moderately deprived animals.
\end{abstract}

Cohen and Quirt (Note 1) recently reported a direct relationship between stimulus-reinforcement association strength and hunger drive in rats. In that study, animals had a brief light change stimulus superimposed on, and paired with, reinforcement at the end of an FR 20 schedule. When this reinforcement signal was tested for nonreinforced evocation of goal approach responses, moderately food deprived animals responded less than highly deprived animals.

Differences between the drive groups in the previous study may be accounted for by differential utilization of exteroceptive and response proprioceptive stimuli. Moderate drive animals may have been more able than high drive animals to utilize number of barpresses to control foodcup approach behavior. Indeed, such a learning strategy may have blocked the moderate drive animals' acquisition of incidental redundant relevant exteroceptive light-off stimulus. An early study by Bruner, Matter, and Papanek (1955) is suggestive that drive level is inversely related to response cue utilization. In that experiment, only moderately food deprived rats were able to utilize an alternation running response in the absence of a formerly redundant relevant brightness cue. Within the fixed ratio situation, two recent studies (Day \& Platt, 1974; Overmann \& Denny, 1974) are also suggestive of the above hypothesis. Overmann and Denny (1974), using food deprived rats at $80 \%$ of body weight, report that only the click of the food dispenser controlled foodcup approach behavior. Day and Platt (1974), using less deprived animals (85\% of body weight), however, demonstrated that rats could use both the exteroceptive food dispenser click and barpress proprioceptive stimuli to control foodcup approaches.

In the present study, we attempted to determine if

The present study was funded by a grant from the National Research Council of Canada (APA 7450). The authors wish to thank Mrs. Anke Oostendorp for her valuable assistance in handling and shaping the animals. The present article was based on a paper delivered at the Southeastern Psychological Association Convention, Atlanta, Georgia, March 1975. method of exteroceptive stimulus presentation would affect its acquisition as a relevant cue by moderately and highly food deprived animals. For half of each drive group (high and moderate), a brief light-off $(.5 \mathrm{sec})$ signal was paired with reinforcement on the last barpress of each fixed ratio (FR 20) run. These drive groups were called response-contingent groups. It was expected that moderate drive animals would be less able to acquire the relevance of the light-off signal than high drive animals, since the moderate drive rats were attending more to response cues. The remaining animals received signal-reinforcement pairings in the absence of operant bar and were labeled the non-(response)-contingent groups. Since the light-off stimulus was paired with reinforcement in the absence of possible competing response cues, moderate drive animals might be expected to acquire the relevance of the light-off cues at least better than the moderate response-contingent rats if not as well as the high drive groups. In the earlier Cohen and Quirt study (1974), test stimuli were presented during signaled FR 20 runs. In the present study, however, nonreinforced test stimuli were presented in the middle of unsignaled runs for all animals. Test stimulus control of foodcup approach behavior was the only indication of light-off cue utilization.

\section{METHOD}

\section{Subjects}

Sixteen male albino rats (Wistar strain) approximately 85 days old at the start of training served as the experimental subjects. These animals were selected from an initial group of 23 rats. Five of the 23 rats failed to reach training criterion, and two other animals died while under high food deprivation.

\footnotetext{
Apparatus

A modified standard Lehigh Valley test apparatus for rats was used. The bar manipulandum was located on the wall opposite the foodcup. An animal pressed the bar while facing away from the foodcup and had to turn around and approach the cup at the end of the operant schedule. A photoelectric unit beam in front of the foodcup measured the approach to the foodcup. The
} 


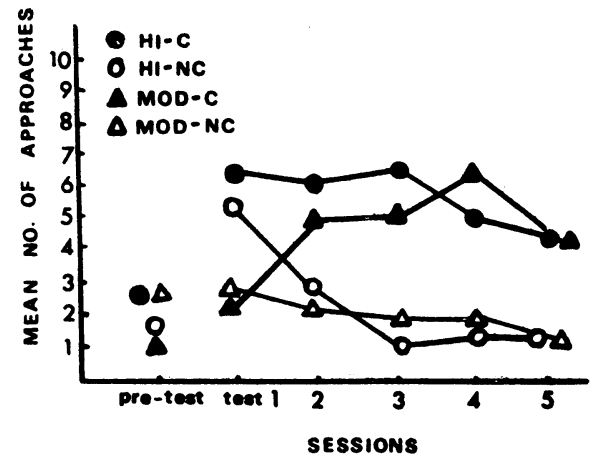

Figure 1. Mean approach frequency to test stimuli during pretest and test sessions for each drive-training group.

photelectric cells were enclosed in clear plastic dividers. These dividers not only prevented investigation of the cells by the rat but focused the rat's behavior to only the foodcup. Thus, a beam break was more likely to be a result of an approach to the foodcup than general investigatory activity of the back wall by the animal. The only source of illumination was supplied by two .04-W lights, each above and to the side of the foodcup. Three such test chambers, each enclosed in a light- and soundproof isolation box, were used. The apparatus were located in a separate soundproof room away from recording and programming equipment.

\section{Procedure}

All animals were first shaped to an FR 20 reinforcement schedule. Each animal received 100 reinforcements $(45 \mathrm{mg}$ Noyes pellets) per experimental session in this and following phases of the study. During bar training days, we gave each animal an additional $7 \mathrm{~g}$ of food per day (Purina Rat Chow) in its home cage after each session. Throughout the study, all animals received water ad lib in their home cages.

We trained each animal on the FR 20 schedule until it reliably approached the foodcup only after the 20th barpress of each FR run. A $90 \%$ approach criterion was originally used, i.e., animals could not approach the foodcup before Response 20 on more than 10 out of 100 reinforced runs. During the course of the study, however, very few animals who reached this criterion were able to maintain it. Although this criterion was kept as an ideal, an animal was also considered to have reliably approached the foodcup at FR 20 termination if its anticipatory approaches occurred after the 18 th barpress. One animal never reached the $90 \%$ criterion but did consistently display anticipatory approaches only after the 18 th barpress. Five animals never reached either criterion with in 22 FR 20 training days and were discarded from the study. Two animals that did achieve foodcup approach criterion died while under high food deprivation. We considered such rigorous shaping procedures necessary in order to decrease the amount of unsignaled anticipatory foodcup approaches, since this response was the dependent variable for testing signal stimulus control of such behavior.

Following shaping and FR 20 training, an animal was randomly placed into either a high (HI) or moderate (MOD) food deprivation group. HI drive animals were maintained on an additional $2 \mathrm{~g}$ of food per day in their home cages following each experimental session. MOD drive animals were maintained on an additional $12 \mathrm{~g}$. These deprivation schedules reduced body weights of MOD animals to a mean of $85 \%$ of starting weights (80\%-91\% range) and of $\mathrm{HI}$ drive animals to a mean of $58 \%$ (51\%-65\% range) of starting weights.

Animals continued to receive unsignaled FR 20 runs for the next 2 days. On the 3 rd day, an animal received a series of 10 nonreinforced test stimuli during the regular session. The test stimulus was $.5 \mathrm{sec}$ light-off that was presented on the 10 th response within some of the FR runs. These test stimuli occurred after the 20th FR run and were separated by three, six, and nine FR runs in a random sequence for an average of six runs. Since the light-off stimulus had never been paired with reinforcement, this session was called the pretest day. It determined the base level of stimulus evoked approaches preceding stimulus-reinforcement conditioning. During test days, the same procedures as described above were also employed. Presentation of test stimuli after $20 \mathrm{FR}$ runs and only on the 10 th response of an FR run further insured against the occurrence of confounding unsignaled anticipatory foodcup approaches. Approximately half of the unsignaled anticipatory approaches occurred during the first 20 FR runs. Furthermore, no unsignaled approaches occurred during the middle of FR runs.

After the pretest day, half of the animals within each drive group received $100 \mathrm{FR}$ runs in which the light-off stimulus occurred on the last response and was immediately followed by reinforcement. This stimulus-reinforcement training was contingent upon the animal's operant response. Animals under these conditions were thus in the contingent (C) training group. The other animals were placed in the test chamber in which the bar was blocked by a wooden panel. Occurrence of the light-off stimulus and reinforcement was contingent upon the responses of an animal in another free operant chamber. This training condition was called the noncontingent (NC) condition. NC animals also received 100 stimulus-reinforcement pairings. NC animals were yoked with animals that showed the same general barpress rate during test sessions. For both training groups, testing sessions within unsignaled FR 20 runs that were similar to the pretest session occurred on the day following the training day. Five such training and test days were run in this sequence. Thus four separate drive training groups, each containing four rats, were used: HI-C, HI-NC, MOD-C, MOD-NC. A Lehigh Valley event recorder measured occurrence of barpresses, reinforcements, the light-off stimulus, and foodcup approaches in each test chamber.

\section{RESULTS}

If an approach response occurred within $2 \mathrm{sec}$ of the test stimulus onset, and without any intervening barpresses, it was considered to have been evoked by the test stimulus. This rigorous criterion insured against any fortuitous unsignaled approaches being counted as test-stimulus-evoked approach responses.

Group results (see Figure 1) showed that animals generally ignored the light-off stimulus on the pretest day. C drive groups increased approaches to the test stimuli while NC animals maintained base levels after training sessions. The only drive level differences occurred on the first test day. HI drive animals within each training group showed increased test-stimulusevoked approach behavior above base levels, while MOD animals maintained base levels. By the 2nd test day, MOD-C animals had also increased such approach behavior above base levels close to HI-C rates and HI-NC animals had dropped down to their base levels.

We carried out a Drive by Training Condition by Test sessions (repeated measure) analysis of variance. In view of the low-frequency scores, we first transformed each 
animal's score to $\sqrt{\mathrm{X}+.5}$, as suggested by Winer (1971). Significant main effects were found for training condition $(\mathrm{F}=15.62, \mathrm{df}=1 / 12, \mathrm{p}<.01)$ and sessions $(\mathrm{F}=3.00, \mathrm{df}=5 / 60, \mathrm{p}<.05)$. A Training Condition by Sessions interaction barely missed significance (observed $\mathrm{F}=2.35$, critical $\mathrm{F}=2.37, \mathrm{df}=5 / 60, \mathrm{p}=.05)$. With individual comparisons (Dunnett's $t$ ), it was found that both HI-C and HI-NC groups significantly increased $(p \leqslant .05)$ test-stimulus-evoked approaches above base levels after the first training session (on Test Day 1). $\mathrm{HI}-\mathrm{C}$ and HI-NC animals returned to levels insignificant from base rates by Test Days 4 and 2, respectively. MOD-C animals significantly increased approaches from base levels from the second test session $(p \leqslant .05)$ while MOD-NC animals never showed any significant increases.

No significant individual comparisons between groups (Newman-Keuls) were found. When training conditions were collapsed, HI animals made significantly more approaches than MOD animals only on the first test day $(\mathrm{p} \leqslant .05)$. With drive level collapsed, $\mathrm{C}$ training animals made significantly more approach responses than NC-trained animals from Test Session 2 through Test Session $5(p \leqslant .05)$.

In view of the small sample size of individual groups, we carried out observational analyses of individual animal's data (see Figure 2). Group differences were not only further confirmed, but other group differences were also uncovered. Within the HI-C group, one animal (No. 2) showed a very high base approach rate; yet, this rat never completely stopped responding to the test stimulus on following days. The lack of habituation suggests that this rat did utilize the light-off stimulus for foodcup approaches. The three HI-C animals that showed little or no base rate approaches rapidly increased and maintained relatively high approach rates. Two of these animals appeared to decrease such approaches by the end of the test sessions, however. MOD-C animals, though, were distinguishable from HI-C animals in their less rapid and more variable development of test-stimulus-evoked approach responses. Only Animal No. 9 behaved similarly to HI-C animals. One animal never developed any appreciable approach response to the test stimuli (No. 20) while another animal only showed a temporary high rate on two later test sessions (No. 8). Animal No. 23 displayed stable high response rates from the second test session on.

NC animals were less varied between drive levels or between individual subjects. Only two HI-NC rats (No. 4 and No. 18) and one MOD-NC (No. 17) rat showed any acquisition of light-off utilization. For the two HI-NC animals, the initial increased approach response on Test Day 1 disappeared by the second or third test session. For the MOD-NC animal, increased approach rates occurred after the second training session (Test Session 2) and disappeared after the fifth training session (Test Session 5). All other NC animals did not show any appreciable approach rate changes from base levels.
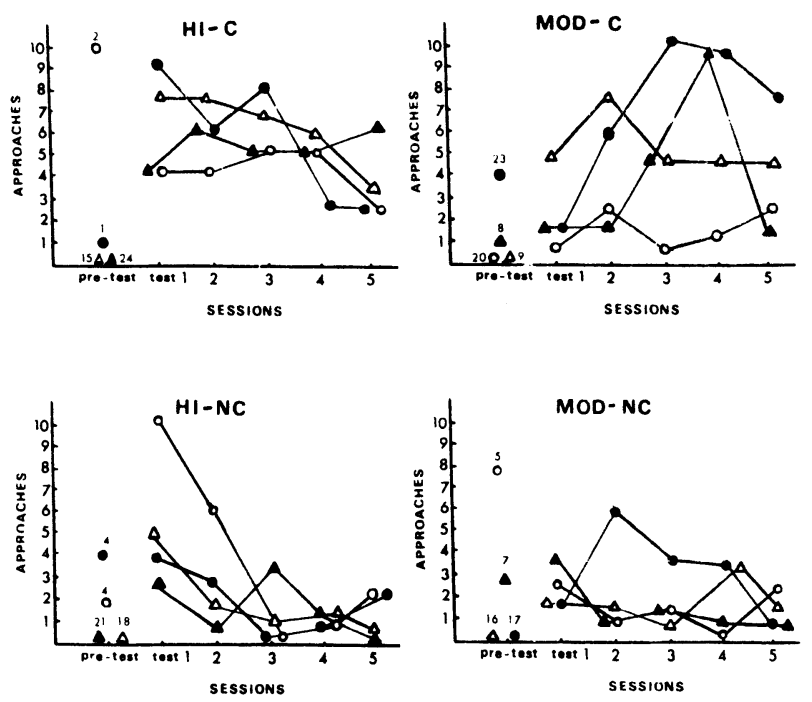

Figure 2. Approach frequencies to test stimuli during pretest and test sessions for each animal in each drive-training group (quadrants). Individual animals are numbered on the pretest symbols.

\section{CONCLUSIONS AND DISCUSSION}

In the present study, animals were more able to utilize a light-off stimulus as a signal for foodcup approach when it was made contingent, along with reinforcement, upon barpressing, than when it was paired with reinforcement in a nonoperant situation. Drive level effects were primarily confined to the contingent condition. HI-C rats developed earlier and more stable light-off utilization than MOD-C animals. Only one MOD-NC and two HI-NC animals displayed initial light-off cue utilization, but such responding rapidly decreased to pretest base rates.

The differences between HI- and MOD-C groups replicates previous results (Cohen \& Quirt, 1974). The question as to whether decreased drive increases utilization of response cues remains open, however, in view of the lack of any development of cue utilization by MOD-NC animals. This finding was contrary to our expectations. We offer three possible explanations for these results. NC animals, in general, may have been unable to acquire the relevance of the light-off cue when other already acquired reinforcement signals such as the bar and responses to it were removed. According to Bolles (1972), expectancy for reinforcement may be a cojoint function of operant responses and exteroceptive signals. A second, but related, possibility is that any light-off-reinforcement associations acquired in the NC situation may have suffered a generalization decrement between acquisition and testing situations for NC animals. This group, during light-off-reinforcement pairings, did not have to face away from the foodcup. During testing, however, all animals received the light-off stimuli while barpressing away from the foodcup. For $\mathrm{C}$ animals, light-off stimuli occurred in a similar situation 
during acquisition and test sessions, i.e., while the rat was barpressing. The third consideration is that $\mathrm{NC}$ animals merely learned to differentially respond to the light-off cue in the acquisition and test situations. In the no-bar situation (acquisition sessions), these animals may have attended to the light-off cue for reinforcement. While in the bar-present (testing) situation, $\mathrm{NC}$ animals may have learned to ignore the light-off cue. Other dependent measures such as decreased latency to the light-off presentations during acquisition sessions in the NC groups, would have supported such a contention. It should be noted that at least three NC animals did display initial testing cue utilization which declined to base levels. These particular animals may have displayed the development of such selective attention to the light-off cue.

\section{REFERENCE NOTE}

Cohen, J. S., \& Quirt, B. M. Secondary reinforcement control of approach behavior as a function of cue salience and drive level. Paper presented at the Canadian Psychological Association Convention, Windsor, Ontario, 1974.

\section{REFERENCES}

Bolles, R. C. Reinforcement, expectancy and learning. Psychological Review, 1972, 394-409.

Bruner, J. S., Matter, J., \& Papanek, M. L. Breadth of learning as function of drive and mechanization. Psychological Review, $1955,62,1-10$.

Day, R. B., \& Platt, J. R. Stimulus control of foodcup approach following fixed ratio reinforcement. Animal Learning and Behavior, 1974, 2, 148-152.

Overmann, S. R., \& Denny, M. R. The free-operant partial reinforcement effect: A discriminative analy sis. Learning and Motivation, 1974, 5, 248-257.

Winer, B. J. Statistical principles in experimental design (2nd ed.) New Y ork: McGraw-Hill, 1971.

(Received for publication March 24, 1975.) 